\title{
RECIPROCIDAD MEDITERRÁNEA.
}

\author{
por
}

\section{GIOVANNI LEVI}

Universidad de Venecia *

RESUMEN: Partiendo de tres conceptos -quidad, analogía y reciprocidad-, el autor se propone mostrar las caracteristicas peculiares de las formas juridicas de las naciones católicas del sur de Europa. Con la mirada puesta en los modelos políticos que subyacen a las concepciones jurídicas de origen teológico del derecbo canónico, el islámico y el judío, sugiere una polarización entre países con derechos fuertes, en los que la ley restringe la capacidad de los jueces para interpretar la ley misma, y países en los que el origen teológico del principio de justicia deja a los jueces un margen muy amplio de interpretación a través de lecturas analógicas y equitativas.

En este esquema tiene un papel central la equidad: la imagen de lo justo que domina una sociedad desigual, jerarquizada y corporativa, pero justa según los principios de la justicia distributiva: a cada uno según su estatus social. Los principios mismos de la reciprocidad deben ser contextualizados en la compleja estratificación de una sociedad desigual, pero equitativa. La presencia de un doble sistema normativo - una ley civil y una ley de origen religioso- junto con la duplicidad de instituciones, produce fragilidad en las instituciones estatales $y$, al mismo tiempo, da lugar a la formación de un sentido común de justicia que muchas veces entra en contradicción con las reglas juridicas codificadas. Hoy, esta antropología también explica muchas de las caracterísicas de las sistemas políticos del Mediterráneo.

Palabras clave: Europa mediterránea. Ancien Régime. Equidad. analogía. Reciprocidad. Concepciones jurídicas. Modelos políticos.

ABSTRACT: Taking three main concepts (equity, analogy and reciprocity) as its strating point of discussion, the autbor shows the particular features of the juridical form of the Catbolic countries in Southern Europe. As political models are influenced by the juridical conception of theological origin in Christian, Islamic and Jewish canon

" Traducción Marco A. Galmarini

Hispania, LX/1, núm. 204 (2000) 103-126 


\begin{abstract}
Law, be suggests a polarization between strong law countries in wbich the law curtails the ability of judges to interpret the own law and countries in which the theological origin of the principles of law confer upon the judger wide atribution of interpretation through analogical and equitative readings.

Equity bas a central role in this view. It is the image which rules an unequal, bierarchical and corporative society which nevertbeless is fair according to the principles of distributive justice: to everyone according to bis social status. In this way, the principles of reciprocity need to be understood in the light of complex stratification of an unequal but equitative society.

The existence of a double normative system, a civil law and a religious law alongside an institutional duplicity produces the fragility of state institutions and provokes the formation of a common sense of justice which many times is contradictory to the juridical rules. An antbropological approach can explain many features of Mediterranean political systems.
\end{abstract}

KEY WORDS: Mediterranean Europe. Ancien Régime. Equity. Analogy. Reciprocity. Juridical conceptions. Political systems.

1. Si queremos emplear el concepto de reciprocidad en sentido concreto y no meramente formal, me parece imprescindible incluirlo en un marco amplio de relaciones jurídicas y económicas respecto de un tiempo y una región de referencia específicos. Por tanto, trataré de mostrar de qué manera ese concepto asume su especificidad en la Edad Moderna, en relación con los sistemas jurídicos que, con expresión inadecuada, llamaré de derecho débil, es decir, sistemas jurídicos en los que predomina la jurisprudencia sobre la ley, en oposición a la acción de los jueces respecto del carácter central del poder legislativo soberano, al que, otra vez inadecuadamente, llamaré sistemas de derecho fuerte. En el área mediterránea es posible incluir en esta categoría de derecho débil por lo menos tres tradiciones -el derecho canónico, el derecho islámico y el derecho talmúdico- que extraen de principios generales de origen religioso las bases inmutables a las que referir las prácticas jurídicas. Y el primer análisis de estos sistemas puede orientarse de acuerdo con tres principios: reciprocidad, equidad y analogía. Un estudioso de la sociedad de Ancien Régime, en particular si se ocupa de países mediterráneos, no puede plantearse la cuestión de las formas de reciprocidad sin referirse a sociedades complejas en cuyo centro se encuentran los mecanismos de solidaridad que caracterizan un proyecto social basado en la justicia distributiva y, al mismo tiempo, en la rígida jerarquización social. Por tanto, la justicia en la desigualdad será el marco en que se insertarán las formas específicas de la reciprocidad en este apunte, que pretende ser más una primera reflexión teórica que la exposición de una investigación verificada en los hechos.

Sin embargo, es preciso decir que el punto de partida de estas reflexiones es un campo concreto de investigación que se puede adoptar como ejemplo para comprender la importancia del problema que me planteo. Hace tiempo que 
estudio el consumo en Venecia de 1500 a 1700 , para responder a una pregunta que parece esencial para comprender la sociedad de Ancien Régime, a saber: ¿cómo se estructura el consumo en una situación en que las diversidades -y ante todo, por tanto, las diversidades de consumo- entre hermanos, entre grupos sociales, entre géneros, se han construido estratégicamente para garantizar la supervivencia? Y también en cómo se pasa de esta sociedad donde la desigualdad es estratégica, aceptada y racional, a una sociedad que gobierna sus comportamientos mediante un idioma - sólo un idioma, que se legitima en las codificaciones- de igualdad entre herederos, entre hermanos, entre grupos sociales e, idiomáticamente, entre géneros. ¿Cuáles son, pues, las formas que adopta la justicia en una distribución desigual de bienes en que los valores de equidad chocan con los de igualdad?

A mi juicio, la llamada revolución del consumo no es en realidad un problema de cantidad, de incremento de las rentas ni de disposición de nuevos bienes, como con harta frecuencia han opinado los historiadores'. Por el contrario, se trata de un problema de lenta transformación cultural de la desigualdad estratégica en igualdad idiomática, transformación que requiere una profunda revolución cultural que implica, y probablemente simplifica, la idea misma de reciprocidad, en la cual la relación de don y contradón resulta menos importante que el sistema global de intercambio en una sociedad gobernada por un sistema aceptado de justicia de la desigualdad ${ }^{2}$.

2. En el centro del discurso debemos poner la equidad, concepto que gobierna algunos de los sistemas jurídicos de los países mediterráneos y ciertos aspectos profundos de la cultura y de la estructura antropológica del sentido común de justicia de las poblaciones mediterráneas. En una sociedad gobernada por la justicia distributiva, esto es, por una justicia que aspira a garantizar a cada uno lo que le corresponde según su estatus social, se complica incluso el modelo polanyiano de reciprocidad ${ }^{3}$, a saber, el movimiento recíproco y bilateral a través del cual pasan los bienes en el intercambio: no se trata sólo de reciprocidad generalizada o equilibrada, sino de una mutiplicación de reciprocidades posibles en las que - en las relaciones de cada grupo con todo otro grupo y en el seno mismo de cada grupo o en el límite de las relaciones de cada persona con todas las otras- las interpretaciones de la reciprocidad se multiplican de acuerdo con significados complejos que mezclan tipo de reciprocidad y nivel social de los protagonistas del intercambio. De esta suerte, todo intercambio mercantil teóricamente equilibrado puede considerar la determinación del pre-

I Cf., por ejemplo, BreWER J.,-PORTER, R., comps., Consumption and the World of Goods, Routledge, Londres, Nueva York. 1993.

2 Cf. LEvl, G., Comportements, ressources, proces: avant la srevolution de la consommation, en J. REVEL, comp., Jeux d'ébelles. La micro-analy'se à lexperience, Gallimard-Le Seuil, París, 1996, pp. 187-208.

3 POLANYI, K., The Livelibood of Man, Academic Press, Nueva York, 1977, pp. 61-74. 
cio según los niveles sociales y las relaciones de los contratantes, y todo intercambio de bienes puede parecer el resultado de una reciprocidad equilibrada o generalizada según quién realiza el intercambio y con quién. De la misma manera, es imposible examinar una sociedad que pone los valores puramente económicos por encima de los valores de buena voluntad y amistad, de don y de contradón, sin tener en cuenta si su finalidad es construir una sociedad de iguales o si, por el contrario, se propone confirmar una estructura social jerárquica ${ }^{4}$.

Quisiera además destacar que se trata de un problema todavia vigente en la sociedad actual, tanto en el terreno jurídico como en el económico. La cultura social católica y a menudo también la socialista, si bien con significados distintos debido a la distinta atención que una y otra prestan a la igualdad, hablan con frecuencia de capitalismo solidario, lo cual es más bien una paradójica figura retórica que un concepto operativo, pese a la importancia de su reflejo en las prácticas políticas. Pero el conflicto entre rigor de la ley y equidad se manifiesta especialmente en la dificultad a menudo comprobada para aceptar la impersonalidad de la justicia, ${ }^{5}$ que tantas veces se discute en nombre de una concepción de equidad que tal vez estaba ya latente al margen de los sistemas jurídicos formales, pero que ahora tiene la posibilidad de expresarse: la indeterminación de los límites que se pone a la ley y el papel del juez en relación con la ley ocupan el centro de la crisis de la justicia en muchos países europeos. Hoy vuelven al centro del debate jurídico y político tanto la intervención de la jurisprudencia en la elaboración del derecho proponiendo interpretaciones,

4 El importante libro de Clavero, B.: Antidora. Antropología catolica de la economia moderna, Giuffré, Milán, 1991, me parece que subestima la necesidad de insertar el don y el contradón en el modelo general de sociedad - jerárquico y protegido- que aspira a construir la segunda escolástica. Dos cosas no comparto con Clavero: la insuficiente evaluación del sentido común de justicia, como si se pudiera explicar las prácticas sociales a través de las leyes y los códigos exclusivamente. En segundo lugar - y como consecuencia - la insuficiente evaluación de la permanencia, en los comportamientos políticos en los países católicos de hoy, de una concepción de justicia en conflicto con las instituciones estatales. Para observaciones muy interesantes sobre la distancia entre la interpretación del derecho del antropólogo y del jurista, véase GEERTZ, C.: «Fact and Law in Comparative Perspective», en GeERTZ, Clifford: Local Knowledge. Furbber Essays in Interpretive Antbropology, Basic Books, Nueva York, 1983, pp. 167-234.

5 En Icalia son frecuentes los movimientos de rechazo a las leyes en nombre de un sentido indefinido de justicia más justa que la ley. Recientemente, un médico, el doctor Di Bella, provocó una auténtica insurrección popular con una manifestación de más de diez mil personas ante el Ministerio de Sanidad y consiguió que dos jueces municipales se pronunciasen a favor de que el sistema sanitario público se hiciera cargo de una terapia suya contra el cáncer que se había demostrado ineficaz. Apagado el caso en Italia, intentó —sin éxito- relanzar la cuestión en otro país católico, Argentina. Hace años hubo un caso de adopción ilegal, anulada por el juez, que dio lugar a una discusión que se prolongó varios meses. Sobre este tema se ha publicado un libro ejemplarmente representativo del sentido común de justicia, escrito por una conocida autora, Natalia Ginzburg, quien sostenía precisamente que *el fin de proteger la universalidad de los niños no justifica una acción cruel realizada sobre la persona de un solo niño [...] Es menester preguntarse cuál es la acción más justa a la luz de la verdadera justician, GINZBurg, N.: Serena Cruz o la vera giustizia, Einaudi, 'Turín, 1990, p. 29. 
como la conciencia de la imposibilidad de individualizar una interpretación única del texto.

La relación entre elaboración, aplicación e interpretación de la ley caracteriza de una manera muy particular la historia cultural de los países del Mediterráneo. Por cierto que no de modo unívoco; sin embargo, tengo la impresión de que los sistemas jurídicos de los países católicos y de los islámicos, en tanto tradición jurídica del judaísmo, han dejado - con grandes variantes, repitomucho espacio a las interpretaciones jurisprudenciales, al uso de la analogía, al papel correctivo de los jueces en el sentido de la equidad a la hora de aplicar a casos concretos la ley demasiado general.

Por tanto, se trata de un problema de carácter más bien antropológico que estrictamente histórico-jurídico. El papel del sentido común de justicia difundido entre las personas que viven en esta área parece particularmente conflictivo en relación con los sistemas jurídicos que se han ido constituyendo sucesivamente. La debilidad de las instituciones en relación con el sentido común de equidad parece asociarse a un papel particularmente fuerte de tradiciones políticas de origen teológico y a la permanencia, en la conciencia común, de la imagen de un pluralismo jurídico que en la multiplicidad de las fuentes de producción de las normas ve en realidad la posibilidad intersticial de moverse con relativa libertad entre sistemas normativos contradictorios, cada uno de ellos ya debilitado y erosionado por la multiplicidad misma. La definición del área que hemos llamado mediterránea, no obstante su dificultad y su gran arbitrariedad, puede encontrarse en todas las realidades en las que, pese a los esfuerzos realizados, no se ha logrado establecer una separación y una jerarquización neta a favor de las instituciones del Estado sobre la presencia de instituciones religiosas. Excluiría de este modelo a Francia, porque la formación del Estado moderno es este país, a través del absolutismo, ha definido precozmente la supremacía de las instituciones del Estado también a nivel del sentido común de justicia.

Una última consideración sobre la importancia del problema. En esta reconsideración de la relación entre justicia e historia, entre tareas del juez y tareas del historiador, no sólo se ha visto implicado el debate reciente sobre la ética y la justicia como equidad, sino también la propia práctica historiográfica reciente; la remisión al sentido común acerca de lo que es justo, la difundida práctica de procesar la historia y el papel jurídico (más testimonios de expertos) que se ha confiado a los historiadores en los procesos recientes por crímenes contra la humanidad, han vuelto a poner sobre el tapete problemas complejos de relación entre sistemas positivos de leyes y sistemas éticos, lo que remite a difíciles operaciones analógicas y a apelaciones a imágenes universales de equidad ${ }^{6}$.

6 Cf., por ejemplo, el dossier Verité judiciaire, vérité bistorique, con artículos de HakToG, F., BaRUCh, M. O., THOMAS, Y., y GaUdARD, P. Y.: en Le debat, 102, 1998, pp. 4-52. 
3. Pero partamos de Polanyi. A pesar de que los comentaristas no lo hayan observado y de que no se pueda encontrar en este autor una elaboración amplia del concepto de equidad, el propio Polanyi ve una estrecha relación entre reciprocidad y equidad: «Para volver a la reciprocidad, un grupo que decidiera organizar las relaciones propias sobre esa base debería, para lograr su cometido, subdividirse en subgrupos simétricos cuyos miembros respectivos pudieran identificarse recíprocamente en tanto tales. Entonces los miembros del grupo A podrían establecer relaciones de reciprocidad con sus contrapartidas del grupo B y a la inversa; o bien puede decirse que tres, cuatro o más grupos son simétricos respecto a dos o más ejes y que los miembros de estos grupos no tienen por qué practicar necesariamente la reciprocidad entre sí, sino con los miembros correspondientes de otros grupos con los que se encuentran en relaciones análogas... lo que da vida a una cadena ilimitada de reciprocidades sin que exista reciprocidad alguna entre ellos». Un sistema de reciprocidades no es, pues, el polvillo de los actos de reciprocidad, de don y contradón, que «tienen lugar en ocasiones diferentes, según un ceremonial que impide cualquier noción de equivalencia, porque a menudo las actitudes personales individuales carecen de efectos sociales». Sólo en un ambiente organizado simétricamente, las actitudes de reciprocidad darán lugar a instituciones económicas de cierta importancia'. Las formas de integración deben crear por tanto un sistema. Y la regla de las sociedades que se basan en la reciprocidad no será la equivalencia, sino la adecuación:

"Mientras que nuestro sentido de justicia busca la adecuación en términos de castigo y recompensa, los movimientos recíprocos de los bienes reclaman la adecuación en términos de don y contradón. En este caso, adecuación significa sobre todo que la persona justa debería recompensar un don con el objeto de tipo justo en el momento justo. Naturalmente, la persona justa es la que se encuentra en una posición de simetría. En efecto, a no ser por esta simetría, sería imposible el funcionamiento del conjunto de las acciones de dar y tomar implícito en un sistema de reciprocidad. A menudo el comportamiento adecuado es el que se inspira en la equidad y la consideración del otro, o que por lo menos parece inspirarse en ella, y, en consecuencia, es diferente de la actitud stricti juris de la ley antigua, que puede ejemplificarse en la insistencia de Shylock en tener su libra de carne. La costumbre de los dones recíprocos no va casi nunca acompañada de duras prácticas contractuales. Sea cual fuere la razón de la elasticidad que lleve a preferir la equidad al rigor, tiende claramente a desalentar las manifestaciones de egoísmo económico en las relaciones de reciprocidad basadas en el dar y el tomar ${ }^{8}$.

Durante mucho tiempo, las sociedades complejas islámicas y católicas han tenido la reciprocidad entre sus imágenes centrales, en un sueño probablemente

7 POLANYI, K.: op. cit., pp. 64-5.

8 Idem. p. 66. El subrayado de equidad es mío. 
irrealizable una vez superadas las pequeñas dimensiones de las comunidades en las que operan simetrías más restringidas, suficientes para sistemas sociales más simples. La fuerza de un poder central, garantía de la justicia distributiva, y la institucionalización de clasificaciones sociales de sociedades jerarquizadas no bastaban para garantizar el funcionamiento de un sistema de integración basado en la reciprocidad, aun cuando la mezcla de mecanismos de integración basada en la redistribución se propusiera convivir con una sociedad en que las células básicas - familia y comunidad- pudieran continuar operando a través de la reciprocidad que emanaba de la buena voluntad y la amistad, la solidaridad y el don- contradón. Y sin embargo - y en esto no estoy de acuerdo con Polanyi- no se trataba de un conflicto entre rigor y adecuación, es decir, entre mensurabilidad de las equivalencias y arbitrariedad relativa del intercambio de dones y contradones: también la equidad ha de tener su medida, un rigor referido a la simetría que gobierna el conjunto del sistema, distinto de la equivalencia. Una medida que se debe establecer caso por caso, transacción por transacción, pero que remite a una percepción social que los protagonistas puedan identificar y que mantenga la equidad de una relación de intercambio entre personas desiguales. «Muchas veces el todo que se da será consecuencia de esta justicia (distributiva); por ejemplo, el soldado sirve bien a su Príncipe o al Capitán por el sueldo establecido, el sirviente sirve bien a su patrón, de quien recibe el salario, o el hijo responde bien a las atenciones paternas; en estricto rigor de justicia comunicativa, que los juristas explican como acción civil, con capacidad para presentarse en juicio, ninguno de ellos podrá aspirar a otra merced, porque ya la ha recibido, y ha hecho lo que debía hacer; pero si el Príncipe, el Capitán, el patrón o el padre, en relación con una diligencia particular, delicadeza en el servicio o atenciones, empujados por aquella obligación natural, que los juristas llaman antidoral, les hacen un donativo, o les conceden otra merced, cometerán un acto de justicia distributiva con tal de que lo ejerzan con aquello de lo que podían disponer libremente sin molestar las posiciones de otro y en la debida proporción de la circunferencia a su centro del mérito, pero no sin esta condición». La justicia distributiva, en efecto, «se asemeja a una esfera cuya circunferencia está regulada por su centro, donde tienen origen todo rayo y toda línea, y es regla bien proporcionada por mucho que sus rayos o líneas se alejan del centro. Por tanto, el mérito o el demérito son el centro de esta justicia, sin los cuales ésta no existe; pero en el modo de quien tiene la potestad para ejercerla, se puede dar mayor alejamiento, de la misma manera en que se da en los rayos o las líneas, sin pérdida de la proporción debida»?. Por tanto, la medida es la proporción, que puede definirse caso por caso a través de la evaluación que sólo una autoridad puede determinar. Pero se trata de una medida

9 DE LUCA, G.B.: $1 /$ Dottor Volgare ovvero il Compendio di tutta la legge civile, feudale e municipale, nelle cose più ricevute in pratica, tomo I, a cargo de Modesto Fenzo, impresor de Venecia, Colonia, 1740, pp. 54-65.

Hispania, LX/1, núm. 204 (2000) 103-126 
exacta, no arbitraria, "puesto que el dar o el premiar sin mérito no será acto de virtud de libertad, sino vicio de prodigalidad, que comporta injusticia al quitar a los meritorios y dar a los que carecen de mérito». El cardenal De Luca parece aquí imaginar un mundo de bienes limitados en el que todo acto de generosidad no sólo premia a alguien, sino que quita a otros. Y esto es precisamente lo que requiere una proporción ponderada. La ley existe, pero es distinta para todos, según las condiciones y los méritos. Sin embargo, requiere el rigor de la proporcionalidad geométrica.

La esfericidad de la justicia distributiva es una metáfora: la esfera es la totalidad, el bien limitado a distribuir en su perfección; pero los méritos y deméritos producen variaciones en la longitud de los rayos. Y también es una metáfora la imagen con que De Luca nos describe la justicia conmutativa y la proporcionalidad aritmética: «Por el contrario, la justicia conmutativa se asemaja a la figura cuadrada, que por necesidad requiere la igualdad y la proporción de las líneas, ninguna de las cuales debe ser mayor que las otras, o bien a la balanza, que para estar en equilibrio debe tener tanto peso en un platillo como en el otro: y en consecuencia, que a cada uno se dé lo suyo y lo que le es debido, pero no más ni menos»10.

Por tanto, no sólo en el seno de la relación entre individuos se puede aprehender la medida, sino también en la coherencia entre los comportamientos individuales y el modelo general que la sociedad prescribe. $\mathrm{Y}$ en este caso se trata de las prescripciones de la teología y de la moral cristiana en sus implicaciones políticas: si no hay en la revelación divina nada de lo cual se pueda deducir una política específicamente cristiana, las instituciones temporales «relinquuntur bumano arbitrio», pero deben tender al bien común político prescribiendo las virtudes y combatiendo los vicios, sea cual fuere la forma preseleccionada entre la pluralidad de formas que la comunidad de los hombres pueda asumir. Por tanto, la libertad de los hombres debe estar presidida por la superioridad moral de la Iglesia, con su función correctiva y de control ${ }^{11}$.

Muchas veces, quienes se han ocupado de la antropología política de las sociedades católicas de Ancien Régime se han sorprendido ante el carácter aparentemente libertario de las reglas sociales: los hombres son completamente libres en sus elecciones, sus sistemas políticos no son creaciones de Dios, sino fruto de su libre albedrío. Pero esta libertad está bajo tutela: como niños que experimentan su relación con la realidad bajo la atenta mirada de los padres, los hombres se aventuran, por su cuenta y riesgo, en la empresa prescrita de formar una sociedad política y económica; pero a la Iglesia, encarnación del poder

10 Idem, p. 66

11 Cf. VILLEY, M.: «La théologie de Thomas d'Aquin et la formation de l'Étar moderne», en Théologie et droit dans la science politique de l'État moderne. Actes de la cable ronde organisée par l'École française de Rome avec le concours du CNRS, Rome, 12-14 novembre 1987, Ecole française de Rorne, Roma, 1991, pp. 31-49. Más en general, cf. Idem, La formation de la pensée juridique moderne, Editions Montchretien, París, 1985. 
directivo y coactivo de Dios, le corresponde la tarea de control y de atracción para dirigir a los hombres, de acuerdo con la ley, hacia la consecución de sus fines sobrenaturales, de los que continuamente se alejan en tanto pecadores ${ }^{12}$. En realidad, el aspecto libertario de la doctrina católica que venden Skinner y Clavero $^{13}$, por ejemplo, sólo es aparente: es la libertad del pecador bajo tutela. Hay, pues, una apariencia de inconmensurabilidad en las relaciones de reciprocidad porque hay una apariencia de libertad absoluta. Pero en ella se oculta un sentido determinado de justicia que se mide en función de la adecuación en la creación de una sociedad jerarquizada y corporativa en que no son justos los actos económicos que tienen como finalidad el enriquecimiento, sino los que tienden a favorecer la circulación de bienes y el bienestar colectivo y desigual, en el que, por tanto, predominen la amistad y la buena voluntad y en el que cada uno tenga lo que le corresponde según equidad, es decir, conservando la proporción respecto de su estatus. En consecuencia, la equidad es un ideal que no se mide sobre la base de reglas abstractas, sino sobre la base de referencias al proceso general de mejora progresiva de la sociedad hacia sus destinos sobrenaturales; no son objeto de medición por parte de los actos particulares, sino de juicio por parte de la Iglesia en su papel de tutora.

Así las cosas, ¿cómo podemos caractizar más detalladamente este concepto de equidad?

4. Es obligatorio remontar el concepto de equidad (epiéicheia) a este conocidísimo fragmento de la Etica a Nicómano: «Lo justo y lo equitativo son lo mismo, y, a pesar de ser excelentes ambas cosas, lo equitativo es mejor. La aporía es producto de que lo equitativo es justo, pero no lo es según la ley, sino que, por el contrario, es una corrección de lo legalmente justo. Causa de ello es que toda ley es universal, pero sobre determinados temas es imposible pronunciarse correctamente en forma universal. Por tanto, en los casos en que es necesario pronunciarse de manera universal, pero, por otro lado, es imposible hacerlo correctamente, la ley tiene en cuenta lo que sucede ordinariamente, sin ignorar el error [...] Por tanto, cuando la ley se pronuncia en general, pero en el ámbito de la acción sucede algo que va contra lo universal, es justo corregir la omisión allí donde el legislador ha dejado el caso a medias y ha errado porque se ha pronunciado en general [...] Por tanto, lo equitativo es justo y es mejor que un cierto tipo de lo justo, no que lo justo en absoluto, sino que el error que tiene como causa la formulación absoluta. Y esta es la naturaleza de lo equitativo, la de ser corrección de la ley en la medida en que ésta pierde valor a causa de su formulación general» ${ }^{4}$. Pero el concepto surgió y tuvo importancia en

12 SKINNER, Q., The Foundations of Modern Political Thought. IL. Age of Reformation, Cambridge University Press, Cambridge, 1978, p. 213.

13 Cf. SKINNER, Q., op. cit. pp. 199-253, sobre el renacimiento del tomismo; y Clavero, B., Antidora, op. cit.

1i Atistóteles, Ética a Nicómaco, libro V, 14, 5-25. 
sociedades que no reconocían la igualdad entre ciudadanos abstractos — según la cual la ley es igual para todos--, sino que, por el contrario, cargaban el acento en la desigualdad de una sociedad jerárquica y segmentada, en que convivían sistemas jerárquicos correspondientes a diversos sistemas de privilegio y de clasificación social: por tanto, una pluralidad de equidades según el derecho de cada uno a que se le reconozca lo que le corresponde sobre la base de su situación social y de acuerdo con un principio de justicia distributiva. En la sociedad de Ancien Régime, el concepto de equidad era el protagonista central de su sueño imposible $\longrightarrow$, mejor dicho, ya imposible - de construir una sociedad justa de desiguales. En ella la imposibilidad no estribaba tanto en el conflicto entre aequitas y aequalitas como en el sueño de que cada uno fuese clasificable con exactitud en un papel o en una condición social unívoca, definida y estable. La ley difiere para cada estrato social, cuando no para cada persona, en una justicia del caso concreto determinado según las desigualades sociales definidas.

A menudo se ha imaginado en la historia del derecho la equidad como mero instrumento con eficacia derogadora del derecho, aunque sin atribuirle naturaleza antijurídica o ilícita ${ }^{15}$. A mí, en cambio, me parece que la equidad -0 , mejor, las equidades - son la raiz misma de un sistema jurídico que aspira a organizar una sociedad estratificada, pero móvil, en la que conviven muchos sistemas normativos en el esfuezo de conocer lo que es justo para cada uno.

No podríamos comprender las revueltas campesinas de la Edad Moderna si las concibiésemos como revueltas contra un sistema estratificado y no como destinadas a obtener lo justo y equitativo para los campesinos en el seno de un sistema de desigualdades aceptadas. Los mismo sucede con las revueltas annonarias, básicas, según Edward $P$. Thompson ${ }^{16}$, para la interpretación de la economía moral del pueblo y que son precisamente revueltas por el precio justo o, mejor aún, por la reafirmación de un sistema adquirido diferenciado y equitativo de precios, pero no movimientos igualitarios o contrarios a la existencia del mercado; para confirmar y no para modificar la estructura social.

Además, me parece que cargar el acento en la equidad contribuye a explicar los esfuerzos clasificatorios que caracterizan a la sociedad de Ancien Régi$m e$, esfuerzos desplegados justamente para definir de manera estable condiciones sociales a las que se reconocen privilegios específicos. Para dar un ejemplo

15 Véase, por ejemplo, las síntesis: CALAsso, F.: «Equità. Premessa storica», en Encidopedia del Diritto, vol. XV, Giuffté, Milán, 1966, p. 65-68; GuARINO, A.: «Equità. Diritto Romanom, en Novissimo Digetto Italiano, vol. VI, Utet, Tutín, 1960, pp. 619-624; Varano, V.: «Equità. Teoria generalen, en Enciclopedia giuridica Trectani, vol. XII, Istituto della Enciclopedia, Roma, 1989, pp. 114.

16 Thompson, E.P., "The Moral Economy Reviews", en Idem, Customs in Common, The New Press, Nueva York, 1993, pp. 259-351. Hasta qué punto los cardenales que administraban la annona romana tenían presente el problema del precio justo de los alimentos se muestra en MARTINAT, M.: «Le blé du pape: système annonaire et logiques économiques à Rome à l'époque moderne», en Annales. Histoire, Sciences saciales, LIV, 1999, págs, 219-244. 
extremo, piénsese en el género pictórico mexicano que floreció en los siglos XVII y XVIII, que reproduce "la sociedad de castas» y que trata de clasificar los efectos de los mestizajes y de los mestizajes de mestizajes entre indios, blan$\cos$, negros y orientales: "de mulato y mestiza produce mulato tornatrás", o «de indio y mestiza nace coyote», o "de español e india nace mestizo; de espanol y mestiza, castizo; de español y castiza, español». Aparte de la necesidad, evidente en el último caso, de certar el círculo con el retorno a lo español, para hacer manipulable, aunque ficticio, un proceso que de lo contrario sería infinito, la clasificación de los mestizajes llega a una lista paradójica que comprende criollo, mestizo, mulato, zambo, castizo, morisco, albino, ahí te estás, albarazado, barcino, calpamulo, cabujo, coyote, chamizo, chino, cholo, grifo, jenízaro, jíbaro, lobo, no te entiendo, salta-atrás, tente en el aire, torna-atrás, zambaigo $^{17}$. Este esfuerzo muestra ya la imposibilidad de crear una clase para cada diferencia, ya la ilusión de que todo individuo podía ser incluido en una clase según una regla uniforme de atribución. Pero los hombres reciben muchos roles al mismo tiempo y crean realidades ambiguas que requieren equidades diferentes, no sólo individuo por individuo, sino también situación por situación. Los archivos de los tribunales de Ancien Régime están llenos de procedimientos en los que los protagonistas hacen su juego intersticial mediante la reivindicación de diferentes pertenencias para gozar de diferentes privilegios; 0 se adscriben a clases impropias por la exigencia de ingresar en el esquema clasificatorio requerido para gozar del mismo privilegio de existencia jurídica ${ }^{18}$. "Que Dante Alighieri estuviese inscrito en el gremio florentino de los médicos y de los boticarios, y que, dos siglos y medio después, Juan Calvino, al llegar como prófugo a Estrasburgo, entrase en el gremio de los sastres, cuando en realidad ninguno de los dos practicó jamás el oficio en cuya corporación había estado inscrito, ha vuelto cuasi proverbial la desconfianza de los historiadores en las cualificaciones corporativas" ${ }^{19}$. Eran simplemente cualificaciones para existir: "en el discurso medieval de la ciudadanía, la visibilidad del sujeto está mediada, pues, por su pertenencia al cuerpo ${ }^{20}$, aun cuando esa pertenencia ordenada fuera ficticia.

5. Pero lo que ahora me interesa no es la historia del concepto jurídico de equidad, sino su importancia tanto para los sistemas jurídicos como para la 1989.

17 Cf. GaRCia SAinZ, M.C., Las castas mexicanas. Un género pictórico americano, Olivetti, Segrate,

18 Una interesance casuística en este sentido, en referencia a los tribunales civiles romanos, puede verse en GropPl, A., «Ebrei, donne, soldati e neofiti. L'esercizio del mestiere fra esclusioni e privilegi (Roma, XVII-XVIII sec.), en GuENZI, A., MASSA P., y MOIOLI, A.: comps., Corporazioni e gruppi professionali nell Lalia moderna, F. Angeli, Milán, 1999, pp. 533-599. Cf. también AGo, R: Economia barocta, Mercato e istituzioni nella Roma del Seicento, Donzelli, Roma, 1998.

is BERENGo, M.: L'Europa delle città. Il volto della società urbana europea tra Medioevo ed Età moderna, Einaudi, Turín, 1999, p. 339.

20 COSTA, P.: Civitas. Storia della cittadinanza in Europa. I. Dalla civiltà comunale al Settecento, Laterza, Roma-Bari, 1999, p. 19. 
elaboración de los sistemas políticos y la realidad antropológica de las sociedades del Mediterráneo. Sin embargo, toda la historia del concepto de equidad puede sintetizarse en dos procesos contrapuestos: mientras que algunos ordenamientos - casi todos los de los Estados modernos continentales - tendían a dejar de lado toda referencia a la equidad, reduciéndola en realidad a instrumento peligroso al que recurrit únicamente en casos extremos de ausencia de reglas en el campo civil, otros ordenamientos - los que cargaban el acento más en el papel de los juicios y la jurisprudencia - tendían a hacer de la equidad un instrumento central de la interpretación y la aplicación de la ley. Tengo la impresión de que precisamente en las sociedades mediterráneas no ha predominado ninguna de estas orientaciones, sino que entre una y otra se ha seguido una historia propia y paralela en las actitudes y en los sistemas informales de derecho, aunque no en los ordenamientos.

Escogeré tres momentos como particularmente significativos. Comencemos por la equidad canónica que ilustran, por ejemplo, Ch. Lefebvre ${ }^{21}, \mathrm{P}$. Fedele ${ }^{22}$ $\mathrm{y}$, con particular atención en el significado político de larga duración del concepto, P. Grossi ${ }^{23}$, a quien remito también para un análisis más profundo. En este momento sólo me urge destacar que la equidad es un elemento central de un sistema normativo que, contraponiendo la inflexibilidad y la inmovilidad abstracta de la justicia divina a la especificidad de la justicia humana, prescribe directamente como deber del juez la aplicación de la ley de acuerdo con los principios de la rationabilitas (esto es, de la conformidad de la razón a la teología), de la salus animarum y de la charitas, y especial atención a la ratio peccatum vitandi y al periculum animae. $\mathrm{Y}$ de ello nace una compleja serie de normas de comportamiento para el juez canónico, que tanta importancia tendrán en las doctrinas políticos de los siglos XVI y XVII: por ejemplo, la tolerantia es en lo esencial la dissimulatio. En particular sería muy útil —-sólo lo digo de pasadaver en qué medida las doctrinas católicas de la razón de Estado y la discusión sobre el disimulo honesto, tomaban muchos de sus elementos constitutivos no sólo de la tradición estoica, sino también de la tradición jurídica canónica. Y esto nos permitiría esclarecer mejor en qué sentido es católica la razón de Estado católica ${ }^{24}$. El disimulo tiene, en la práctica canónica, un fin fundamentalmente positivo, ligado precisamente a la gestión de la justicia en estricta referencia a la contextualización de los casos singulares, en función de una mejora

${ }^{21}$ LEFEBVRE, Ch.: «Le rôle de l'équité en droit canonique, en Epbemerides itris canonicì, VI, 1951, pp. 137-153.

22 FEDele, P.: «Equità canonica», en Encidopedia del diritto, vol. XV, Giuffré, Milán, 1966, pp. $147-159$.

23 Grossi, P.: L'ordine juridico medievale, Laterza, Roma-Bari, 1995, pp. 203-222. Por el contrario, en Gaudemet, J.: Église et Cité. Histoire du droit canonique, Cerf-Montchrestien, París, 1994, se soslaya por completo la importancia del problema.

24 LeFEBVRE, Ch.: «Dissimulation», en Dictionnaire de théologie catholigue, Table général, Tome I, Letouzey, París, 1951, pp. 1008-9.

Hispania, LX/1, núm. 204 (2000) 103-126 
moral general. Por tanto, no me parece suficiente verlo como técnica política de dominio, como hace, por ejemplo, Villari cuando comenta Della dissimulazione onesta, de Torquato Accetto, en estos términos: «Concebido por el pensamiento clásico y medieval como problema eterno del hombre, de la relación entre apariencia y realidad, entre mentira y verdad, a finales del siglo XVI y durante el siglo siguiente se lo consideró sobre todo como un aspecto específico de la vida política y de la costumbre de la época» 25 , tanto que "también el mundo de la oposición y de la resistencia activa al poder recibió e hizo suya una técnica elaborada oficial y exclusivamente para la acción de gobierno" ${ }^{26}$. Precisamente en los límites del disimulo estriba el problema central de su legitimidad y su honestidad, límites que tienen su definición en la práctica jurídica católica. El que se traduzca en técnica de gobierno o de resistencia al poder, pasando por Maquiavelo, no afecta en lo fundamental a la relación de la razón de Estado católica con los orígenes jurídico-canónicos ${ }^{27}$.

Grossi habla de la «notable influencia del derecho canónico clásico en el desarrollo de toda la juridicidad occidental. La posición central de la equidad canónica, verdadera norma constitucional no escrita; el sentimiento constante de la mutabilidad del derecho humano; la consiguiente y forzosa elasticidad de éste y el importante papel del juez que lo aplica: he aquí puntos firmes que, al desbordar los términos cerrados de la sociedad eclesial, penetrarán en el orden jurídico de la sociedad civil, lo solicitarán, lo impregnarán» ${ }^{28}$. Pero vale la pena destacar que no se trata tan sólo de relación entre orden jurídico canónico y civil, sino también de influencia de la concepción de unidad en un campo menos definido, como es el del sentido común de justicia, el modo de percibir lo justo y lo injusto de las sociedades católicas y, por tanto, el modo de relacionarse con el Estado y sus instituciones. Convivencia compleja que - no obstante los ordenamientos y las codificaciones - no se resuelve en una sucesion de concepciones jurídicas: de hecho, en el sentimiento común conviven «nuestra igualdad formal, abstracta, igualdad jurídica de sujetos en realidad desiguales y que siguen siendo desiguales a pesar de la cínica afirmación de principio» y «la igualdad que la aequitas pretende garantizar y que, por el contrario, es pura sustancia [...] la unicidad del sujeto - del sujeto civil abstracto- es un futurible de las invenciones iluministas. No existe aquí el sujeto, sino los sujetos, y sujetos bien encarnados, con toda su carga de facticidad, es decir, de inmersión en los hechos" ${ }^{29} \mathrm{y}$, por tanto, de estatus y de roles diferentes.

25 VIILARI, R.: Elogio della dissimulazione. La Lota politica del Seicento, Laterza, Roma-Bari, 1987, p. 18. Tampoco me parece que encare este problema Borrelll, G.: Ragion di stato e Leviatano. Conservazione e scambio alle origini della modemità politica, Il Mulino, Bolonia, 1993.

26 VILLARI, R: $o p$. cit, p. 25.

${ }_{27}$ OLlvero, G.: Dissimulatio e tolerantia nellordinamento canonico, Giuffré, Milán, 1953.

${ }_{28}$ Grossi, P.: op. cit., p. 216 . La referencia es también a la equity del sistema jurídico inglés, que sin embargo no estudiaremos aquí, pues nos alejaría demasiado de este análisis mediterráneo.

29 Grossi, P.: op. cit., 179. 
La equidad no se propondrá sin gravísimos conflictos: la conciencia que la equidad contrapone a la concepción misma de Estado moderno, y en particular a la monarquía absoluta, se abrirá camino poco a poco. De la misma manera, cada vez será más evidente la explícita contradicción entre el poder del juez en la aplicación equitativa de la norma y la seguridad del derecho.

6. Podemos ejemplificar esto con Bodin, que en la interpretación de los jueces de acuerdo con la equidad veía precisamente una amenaza al principio mismo de soberanía: en la base misma de las teorías absolutistas reside la contradicción que deriva de la interpretación de la ley y de la aplicación equitativa de las normas como modo de operar de los jueces. En el primer libro de La République, capítulo X, Bodin define «las verdaderas marcas de soberanía». «La première marque du prince souverain, c'est la puisssance de donner loi à tous en général et á chacun en particulier [...] sans le consentement de plus grand, ni de pareil, ni de moindre que soi [....] La seconde marque de majesté.. décerner la guerre ou traiter la pax [...] La troisième marque de souveraineté est d'instituer les principaux officiers [...] Ce n'est pas l'élection des officiers que emporte droit de souveraineté, (mais) la confirmation et provision [...] L'autre marque souveraine, c'est à savoir du dernier ressort, qui est et a toujours eté l'un des principaux droits de la souveraineté [...] La cinquiéme marque de souveraineté $[\ldots .$.$] la$ puissance d'octroyer grâce aux condamnés par-dessus les arrêts et contre la rigueur des lois, soit pour la vie, soit pour les biens, soit pour l'honneur, soit pour le rappel du ban». Todos estos signos de soberanía, que dejan la acción derogatoria de la ley a discreción del soberano, aunque dentro de los límites de la equidad, son inalienables. Sólo un aspecto de la equidad escapa al soberano: «Mais entre les marques de souveraineté, plusiers on mis la puissance de juger selon sa conscience: chose qui est commune à tous juges, s'il n'y a loi ou coutume expresse [...] S'il y a coutume ou ordonnance au contraire, il n'est pas en la puissance du juge de passer par-dessus la loi, ni disputer la loi [...] Mais le Prince le peut faire si la loi de Dieu —única limitación a la soberanía - n'y est expressen ${ }^{30}$.

30 BODIN, J.: Les six livres de la République, libro I, cap. 10. He aquí la traducción castellana de la cita. Primer bloque, hasta «le rappel du ban»: «La primera marca del príncipe soberano es el poder para dar la ley a codos en general y cada uno en particular [...] sin consentimiento mayor, par ni menor en relación a él [...] La segunda marca de majestad [...] declarar la guerra o convenir la paz [...] La tercera marca de soberanía es la de instituir los principales funcionarios [...] No es la elección de los funcionarios lo que comporta derecho de soberanía, (sino) su confirmación y su provisión [... L La otra marca soberana es la instancia última, que es y siempre ha sido uno de los principales derechos de la soberanía [...] La quinta marca de soberanía [...] el poder de otorgas gracia a los condenados, por encima de las sentencias y contra el rigor de las leyes, sea para la vida, los bienes, el honor o el regreso del destierro». Segundo bloque («Mais... n'y est expresse»): «Pero entre las marcas de soberanía, hay quienes han puesto el poder de juzgar según conciencia: lo que es común a todos los jueces en caso de no haber ley ni costumbre expresa [...] Si hay costumbre a ordenanza en sentido contrario, el juez no tiene poder para pasar por encima de la ley, ni para discurir la ley [...] 
De todo esto se deriva la rígida actitud con que Bodin limita la interpretación de la ley, dejando a la conciencia de los jueces la tarea de juzgar sólo en ausencia de ley y nunca en oposición a la ley. Por tanto, no se consiente a los jueces la aplicación desigual de la ley según la variedad de lugares, momentos y personas; la equidad, en cambio, es el principio propio del soberano, a quien, precisamente en función de la exclusividad de los derechos que definen la soberanía, primero entre todos y del que los otros aspectos sólo son especificaciones, se consiente que haga las leyes. La interpretación y la aplicación equitativa de la ley transformarían de algún modo al juez en legislador, lo que disolvería la soberanía.

Pero, cen qué consiste la equidad para Bodin? Lo aclaratá en el capítulo VI del Libro Sexto. La característica de la justicia distributiva y de la proporción geométrica es una igualdad geométrica que gobierna este tipo de justicia, típica de la sociedad aristocrática y jerárquica, en la que cada uno tiene derechos diferenciados y todo semejante en estatus debe unirse y ser tratado con sus semejantes. Tiene muchos aspectos de equidad, pero no puede funcionar por sí sola debido a su rigidez, «la fermeté de la règle de Polyclète». A esto se opone la igualdad de la proporción aritmética de la sociedad democrática, que no acepta diferencias de estatus, se basa en la justicia conmutativa y está en poder «de la variété et incertitude de la règle Lesbienne». En contraste con las dos formas de justicia aristotélica es preciso, pues, «suivre la justice harmonique, et accoler ces quatre points ensemble, à savoir Loi, Equité, Exécution de la loi, et le devoir du Magistrat». Y la justicia armónica, que es la proporción que funde ambas igualdades, es la equidad garantizada por la soberanía absoluta del príncipe, el único que puede «accomoder l'équité à la varieté particulière des lieux, des temps et des personnes ${ }^{31}$.

7. Durante todo el siglo XVII — de Hobbes a Leibniz- el sueño de una ley tan simple y clara que redujera el papel de juez al de mero agente de aplicación mecánica de las normas dominaría las escuelas fundamentales del pensamiento jurídico-político. Ya se trate de las interpretaciones voluntaristas y nominalistas de la justicia para las que las cosas son justas porque así lo ha querido Dios, ya de las interpretaciones esencialistas o realistas, para las que Dios ha querido que las cosas fueran así porque eran justas, ya de las interpretaciones del positivismo jurídico que dejan a la voluntad del hombre la creación

Pero el Príncipe lo puede hacer si la ley de Dios -única limitación de la soberanía- no es expresa al respecton.

${ }^{31}$ BODIN, J.: op. cit., libro VI, cap. 6. Sobre Bodin y la equidad, véase BEAUD, O.: La puissance de IÉtat, Presses Unviersitaires de France, París, 1994, pp. 191-196. Traducción de las cuatro citas en francés de este párrafo: «la inconmovible ficmeza de la regla de Policleto"; "de la variedad e incertidumbre de la regla lesbiana»; «seguir la justicia armónica y reunir los cuatro puntos, a saber, la Ley, la Equidad, la Ejecución de la ley y el deber del Magistrado" y «acomodar la equidad a la variedad particular de lugares, momentos y personas". 
de las normas jurídicas para que sirvan a sus apetitos en las cambiantes circunstancias de la vida, todas tienen en común la idea de que hay una única fuente de justica y que, por tanto, es posible crear una justicia exacta y uniforme. La justica distributiva tiende a desaparecer de los objetivos del derecho propiamente dicho, del jus strictum ${ }^{32}$, mientras que la equidad tiende a ser teabsorbida en la justicia como la moral y la voluntad en la razón, sin contrastes. En sus reflexiones jurídicas, por ejemplo en las Meditaciones sobre el sentido común de justicia (1702 c), Leibniz llega a lo que tal vez sea la posición más extrema cuando sueña con una justicia prácticamente mecánica, de acuerdo con su teoría lógica que buscaba la coordinación rigurosa ente signo y significado, que fijara de una vez para siempre la proporción entre caracteres y cosas, que es el fundamento de la verdad. La justicia es una de las «ciencias necesarias y demostrativas que no dependen de los hechos, sino únicamente de la razón, como lo son la lógica, la metafísica, la aritmética, la geometría, la ciencia de los movimientos y también la ciencia del derecho, que no se fundan en la experiencia y los hechos y sirven más bien para explicarlos y regularlos por anticipado, lo que también valdría para el derecho si no hubiera leyes en el mundo». En consecuencia, éste es el objetivo por ahora no realizado, pero que podrá serlo cuando los hombres se sometan a la ley de Dios y a la razón. De esa suerte, "cuando surjan controversias ya no serán más necesarias las disputas entre dos filósofos que entre dos calculistas. En efecto, bastará con coger la pluma, sentarse ante el ábaco y decirse recíprocamente: calculemos». (De scientia universarlis) ${ }^{33}$.

La equidad, la interpretación equitativa, son, en consecuencia, soluciones subalternas y parciales en un mundo imperfecto que todavía tiene que recurrir a una distinción entre strictum jus, bondad y equidad. El concepto de equidad ha comenzado así un proceso progresivo de marginación y de reducción, cuyo desarrollo no seguiré porque nos alejaría mucho de las costas mediterráneas.

Pero no ocurre lo mismo en Italia y en España, sociedades en las que el derecho canónico conserva una presencia notable en el sentido común y en la realidad cotidiana. La acción de la Inquisición y la práctica de la confesión, del arrepentimiento y del perdón, difundida por doquier, no pudieron haber dejado de incidir, en un nivel inconsciente, en el sentido común de justicia que el tribunal de las conciencias sugería a los fieles. Así se creó una cultura específica, que poco a poco se convirtió en antropología concreta, sentido muy extendido de un doble valor de la moral, de un significado distante y débil de las instituciones del Estado.

32 La búsqueda de una distribución justa de los bienes sería sin duda un objetivo demasiado ambicioso para el jurista y que, o bien no forma parte de sus tareas, o bien carece directamente de todo sentido para él. Grocio descarta la justicia distributiva del campo del derecho propiamente dicho. M. VILLEY, M.: La formation, op. cit., p. 529.

33 LEIBNIZ, G. W.: Le droit de la raison, textos reunidos y presentados por SÈVE, R, VRIN, J.: París, 1994, pp. 107-136. 
8. De esto se daba cuenta Vico - que utilizaré como último ejemplo de la evolución comparada del significado de la equidad-, muy influido por el sentido católico de la comunidad política en camino hacia la redención, esto es, «el progreso no interrumpido de toda la historia profana». La semejanza con Leibniz es mera apariencia: para el primero, la equidad desaparece en la ley, mientras que para el segundo, la ley desaparece en la equidad. En De universi iuris uno principio et fine uno $(1720)^{34}$, Vico divide el derecho natural en jus naturale prius y jus naturale posterius, donde el primero muestra al individuo en su exigencia de conservación, para la cual el criterio individual de cada uno, dirigido a la conservación, hace las veces de norma. En su curso, la historia tiene la función de desvelar progresivamente un orden natural diferente, fundado en la capacidad de la razón para transformar el principio de conservación individual en colectivo, es decir, referido a los cuerpos sociales. Este proceso pasa por el jus gentium y el desarrollo del derecho civil, que transforman la lucha de todos contra todos en relaciones de protección basadas en el dominio y la subordinación. De la equidad natural del jus prius, que se contrapone a la verdad porque «ex ipsa bominis sociali natura duplex existit naturalis rerum societas: altera veri, altera aequi boni ${ }^{35}$,Vico nos conduce a la equidad civil: parte de la descripción de la jurisprudencia benigna o ateniense y del jus pretorio, en el que «el vulgo (es) sensible a la equidad natural e ignora la equidad política (vulgus naturalis solers, civilis aequitatis ignarum)". Con el mantenimiento invariable de las fórmulas de las acciones — según las XII tablas- el pretor proveía a la estabilidad de la región civil, y con las excepciones, cuando se trataban cuestiones no contenidas en las XII tablas o cuando la ley de las XII tablas resultaba demasiado dura (si aequitati lex surda durave esset) les introducía, en caso de necesidad, la equidad del jus naturale $e^{36}$. Así se introduce una jurisprudencia benigna, "ars adqui boni", según la definición de Celso. La equidad natural se caracteriza, pues, por acoger muchas excepciones a las reglas que la ley expresa, porque en el jus naturale prius domina todavía un hiato entre individuo y conveniencia racional. La equidad civil, en cambio, parece y es autoritaria, por lo que «muy a menudo recibe el nombre de rigor de la ley porque el rigor civil que se sufre inmerecidamente es muy grave y amargo (magis appellata est «iuris rigor», quia civilis rigor est sane rigor in causis in quibus contra immerente duratur) ${ }^{37}$. Sólo con el desarrollo de la racionalidad y la communitas, el derecho natural posterius hace coincidir aequitas y ley. Pero se trata de una aequitas que tiene su raíz en la aequitas natural, que la comunidad consiente realizar. «El alma de una república es el derecho equitativo para todos, cuya idea - como hemos demostrado- es una idea eterna

34 VICO, G. B.: De universi iuris uno principio et fine uno, en Opere giuridiche. Il diritto universale, a cargo de Cristofolinl, P.: Sansoni, Florencia, 1974, pp. 17-346. La traducción italiana es de Carlo Sarchi, P. Agnelli, Milán, 1866.

35 Idem, p. 65.

36 Id., p. 283-5.

37 Id., p. 289.

Hispania, L.X/1, núm. 204 (2000) 103-126 
que viene de Dios. Por tanto, hemos concluido que la constitución eterna de la república es el orden natural y que, en consecuencia, el alma de la república no es equitativa para la equidad civil, sino para la equidad natural (Animus reipublicae ius aequum omnibus, cuitus ideam aeternam a Deo esse demonstravimus. Unde formam rerumpublicarum aeternam ordinem naturalem esse confecimus; ac proinde animum reipublicae non esse aequum aequitate civili, sed aequitate naturali) ${ }^{38}$, porque el derecho existe en la naturaleza (ius esse in natura) y es demostrable matemáticamente. "At quod est aequum dum metiris, idem est iustum quod eligis»" ${ }^{39}$. Por tanto, el pasaje del jus prius al jus posterius marca el pasaje de una equidad natural individual a la equidad natural absoluta, pasando por la equidad civil. Porque la equidad civil expresa la manipulación autoritaria de la seguridad de la ley que justifica la razón de Estado: eatque baec est aequitas civilis, qua Iustinianus in Novellis dicit niti usucapiones, et «impium praesidium» eleganter appellat, quam Itali elegantiori phrasi vertunt "razón de Estado»" ${ }^{40}$. El proceso de civilización nos lleva, pues, de la utilidad privada a la pública, en la que se funden el sentido (utilidad y necesidad) y la razón bajo el dominio de esta última y en polémica con el jus naturale philosophicum de Grocio, que reducía sólo a la razón la fase final del sistema jurídico en que coincidían aequum y justum. «Eiusque iurisprudentiae regula aeterna est aequitas naturalis, quae multa contra communes iuris regulas recipit et admittit ac iuris civilis rigores temperat. Sed ea ipsa durior est iuris rigor (...) neque enim ex suo iure immutabili quequam solvit, nec ullum unquam bominis meritum tantum est ut ratio naturalis ipsi indulget quod non dictet bonestas. Tamen totius generis nomen occupavit; et adquitas civilis magis appellata est «iuris rigor», quia civilis rigor est sane rigor in caussis in quibus contra immerentes duratur. At aequitas naturales ex genere "aequitas» dicta est, quia in ipsis caussis in quibus immota baeret - baeret autem in omnibus - in ipsis, inquam, caussis benigna est. Et parvum est bominum iudicium qui eam iniquo animo ferunt, nam de ea sensuum sapienta, quam stultitiam definivimus, iudicant»" 1 .

En Vico - y especialmente en el Vico de De universi iuris uno principio et fine uno- es muy marcada la inspiración en el cosmopolitismo católico y el pensa-

\footnotetext{
3日 De constantia jurisprudentis, ivi, p. 381.

39 Idem, De universi, op. cit., p. 57.

40 Idem, p. 261.

41 Idem, p. 289. "La norma eterna de una jurisprudencia así realizada es la equidad nacural, y por eso recibe y acoge muchas excepciones a las reglas que la ley expresa, y se esfuerza en aremperar los rigores de la razón civil. Pero por su propia condición, la equidad narural implica un rigor más inflexible aún; no excluye a nadie de su ley inmutable, y a ningún hombre puede la razón natural complacer con el alejamiento de la honestidad, pues la equidad natural es el nombre genérico, que comprende todas las formas de lo equitativo. Que la equidad civil reciba más a menudo el nombre de "rigor de ley" se debe a que el rigor civil sufrido inmerecidamente es muy grave y amargo, mientras que, por el contrario, la equidad natural, esto es, la «equidad» genérica y absoluta, se muestra siempre benigna incluso en las causas en las que se muestra más estrechamente unida ( $y$ en todas se la encuentra); y perverso es el consejo de quienes la toleran de mala gana, porque tienen el juicio ofuscado por la sabiduría de los sentidos, que hemos definido como estultician.
} 
miento político tomista cuando describe el proceso que, a través de la realización progresiva de la communitas entre los hombres dominados por las pasiones y el pecado, lleva a la explicitación de una racionalidad común, que progresivamente elimina la fuetza de las relaciones entre los hombres. En resumen, una racionalidad que conoce un desarrollo paralelo al desarrollo de las formas de convivencia social.

9. La finalidad de los ejemplos que he examinado eta mostrar que las imágenes de justicia que se van estructurando en la Edad Moderna en los países europeos y en los del Mediterráneo nacen de modos diferentes de enfrentar la oposición entre ordenamientos que, reforzando el peso de la ley, se abren paso poco a poco hacia la codificación y el ordenamiento que refuerzan - sin renunciar a una cierta forma de medida y de seguridad del derecho- el poder interpretativo de los jueces en las prácticas judiciales. De esta suerte, el problema se va concentrando en el espacio concedido a los jueces ante los casos no previstos explícitamente por la ley o de difícil reducción a los principios fundacionales del ordenamiento: es así como el concepto de analogía viene a cumplir un papel muy importante, ya sea en su forma más limitada de analogia legis, ya sea en la más general de analogia iuris.

El procedimiento mediante el cual se busca la disciplina del caso no regulado puede adoptar tres formas: la interpretación extensiva, que no tiene carácter integrador, sino interpretativo; la remisión a los principios generales del ordenamiento, con un papel interpretativo e intregrador, y la analogía, cuya función es integradora ${ }^{42}$. Sólo me detendré en la analogía, dada la particular claridad con que, en lo tocante a este concepto, se muestran las tendencias contrastantes de los sistemas jurídicos; en efecto, mientras que, desde el punto de vista del análisis teórico, la analogía ha desempeñado un papel cada vez más limitado en los sistemas jurídicos europeos, ha ido en cambio aumentando su importancia en los ordenamientos del derecho hebreo, el islámico y el canónico.

En general, podemos decir que el problema central en la evolución hacia la codificación de los ordenamientos jurídicos ha sido el de la limitación de la analogía en dos direcciones. Mientras, se ha ido dando una definición cada vez más estrecha de analogía, esto es, quitándole ese carácter un tanto indefinido de semejanza que ya habían combatido el tomismo y después Cayetano ${ }^{43}$. El con-

42 BobBlo, N.: «Analogia», en Novissimo Digesto Italiano, vol. I, Utet, Turín, 1960, págs, 601606. Cf. también CARCATERRA, G.: "Analogia», en Enciclopedia Giuridica Reccani, vol. II, Istituto della Enciclopedia, Roma, 1988, pp. 1-25, con particular referencia a la relación entre equidad y analogía, pp. 12-14.

${ }_{33}$ Cf. Secretan, Ph.: L'analogie, Presses Universitaires de France, París, 1984. Sobre las posiciones de Tomasso de Vio Cayetano a propósico de la analogía, véase NEF, F.: «La rationalisation analogique en question? A propos de la théotie cajétanienne de l'analogie», en Rationalisme analiogique et bumanisme théologique. La culture de Thomas de Vio aEl Gaetanow, Actes du colloque de Naples 1-3, noviembre de 1990, Vivarium, Nápoles, 1993; RIVA, F.: Analogia e univacità in Tommaso de 
cepto mismo de analogía va perdiendo poco a poco la indefinición de la semejanza para convertirse en un concepto exacto de proporción. Analogía - -dirá Kant- no significa, "como suele interpretarse la palabra, una semejanza imperfecta de dos cosas, sino una semejanza perfecta de dos relaciones entre cosas incluso completamente diferentes»; esto es, precisamente, la proporción $n^{44}$. Y se recordará que para el cardenal De Luca la proporción también es la regla geométricamente exacta de la justicia distributiva y de la equidad.

La segunda vía, más explícita, aunque conserva el carácter de la semejanza como fácticamente definitorio de la analogía, ha sido la de poner límites al uso de las prácticas judiciales, excluyéndola especialmente del peligroso camino de las leyes excepcionales y del derecho penal, con mayor razón en el caso de leyes penales incriminatorias ${ }^{45}$.

Por el contrario, es preciso destacar que todos los ordenamientos que tienden a la individualización de la pena, de gran predominio en las sociedades desiguales y jerárquicas del Ancien Régime, utilizan con amplitud la analogía ${ }^{46}$. Precisamente con referencia a la consideración subjetiva del delito, a su diferenciación de acuerdo con los momentos, los lugares y las personas, a la diferencialidad social de conjunto del sistema jurídico, la equidad impone el procedimiento analógico como instrumento central de derecho. No es necesario recordar el papel central de la analogía (qiyâs) en los sistemas jurídicos islámi$\cos ^{47}$, en los que constituye una de las cuatro fuentes de la ley musulmana, referida a los casos en que no exista una prescripción textual explícita del Corán o de una tradición. En realidad, el razonamiento analógico contiene un vigoroso elemento de inseguridad y permite, por ejemplo, interpretaciones diferentes. Sin embargo, remite rigurosamente a los deberes morales de los jueces y a la equidad: en efecto, coincide con el esfuerzo de investigación personal (ijtihâd $)^{48}$.

Vio «Gaetano», Vita e pensiero, Milán, 1955. Sobre Tomás de Aquino y Suárez, C€́. BASTIT, M.: Naissance de la loi moderne. La pensée de la loi de Saint Thomas à Suárez, Presses Universitaires de France, París, 1990.

44 El Kant de los Prolegomena zu einer jeden kïnftigen Metaphysik die als Wissenschafi wird aufreten können (1783) es cirado por NEEDHAM, $\mathbf{R}$, en si importante ensayo sobre analogía titulado: "Analogical Classification", en Reconnaissances, University of Toronto Press, Toronro-Buffalo-Londres. 1980, págs, 41-62.

45 Cf. Vassalli, G.: "Analogia del diritto penale", en Novissimo Digesto ltaliano, vol. I, op. cit, pp. 607-611.

46 Sobre semejanza y analogía en la sociedad moderna es útil referirse también al capítulo 2, «Les quatre similitudes», de Foucault, M.: Les mots et les choset, Gallimard, París, 1966.

4" Véase la voz "Kiyas", redactada por BERNARD, M.: en The Encyclopedia of Islam, vol. V, Brill, Ieiden, 1980, pp. 238-242. Cf. también SCHACHT, J.: An Intraduction to Islamic Law, Clarendon Press, Oxford, 1964, pp. 64-75; Coulson, N. J.: A History of Islamic Law, Edimburgh University Press, Edimburgo, 1964, p. 59-60; BRUNSCHVIG, R.: Études d'islamologie, Maisonneuve et Larose, París, 1976, vol, I, pp. 303-327; vol. II, pp. 347-403.

48 En uno de los textos fundadores de la metodología jurídica islámica, Muhammad Ibn Idrîs Ash-Sâfî î (767-820) define con claridad tanto el razonamiento analógico como el esfuerzo de inves- 
Pero el foco de toda la discusión sobre la analogía está ocupado por el problema de la seguridad y la uniformidad del derecho: aun cuando el papel interpretativo del juez sea en realidad amplísimo, el problema de la proporción entre las penas y la seguridad se desplaza —en el caso del derecho islámico- al testimonio, a la multiplicidad de las pruebas, a la confesión del reo y a la coherencia con los principios y las reglas del derecho de Dios.

Problemas análogos presenta el papel de la analogía (béqèsh y gezéra chava) en la exégesis jurídica del derecho talmúdico, en el cual el razonamiento analógico lleva a conclusiones probables porque se basa en semejanzas y no en la identidad matemática de la proporción. Por tanto, tiene carácter orientativo e hipotético. Pero - como nos lo recuerda Weingort-, la analogía es un instrumento necesario para el procedimiento mismo con el que los Amoraim los redactores del Talmud- construyeron las reglas generales. «El Talmud emplea la forma casuística, gracias a la cual, con uso del método inductivo, el principio general abstracto se extrae a partir del caso particular. El Talmud, por tanto, debe asegurarse de que el caso particular que cita como ejemplo del principio general ilustre un principio legal y sólo uno, con exclusión de cualquier otro. Esto únicamente es posible mediante la elaboración de modelos que respondan al criterio de excluir cualquier enseñanza distinta de la que los $\mathrm{Sa}$ bios han querido [...] Esta formulación artificial, en oposición a los casos de la vida real, permite hacer abstracción de los detalles concretos que podrían producir, por contacto, un principio distinto del deseado ${ }^{49}$. Pero esto admite tanto una referencia continuada a la equidad como un uso extenso de la analogía. Mejor dicho, una verdadera proliferación de la analogía: en todo el debate jurídico talmúdico se van desarrollando progresivamente reglas específicas que consienten la analogía, a menudo distintas tanto de la semejanza como de la proporción, como, por ejemplo, cuando se afirma (como ocurre en las siete middot de Hillel el Antiguo) la analogía de lugares bíblicos sobre la base de la semejanza fonética de las palabras o la analogía de dos disposiciones, a pesar de su gran diferencia, por su presencia en el mismo versículo bíblico. En resumen, tanto en el derecho hebreo como en el resto de la hermenéutica talmúdica, la analogía desempeña un papel básico. Pero - a diferencia de la tradición lógica aristotélica- su caracterización también toma forma en obediencia a reglas que detivan de la sacralidad del texto de referencia, en el que cuentan elementos de vecindad y distancia entre palabras, semejanza fonética o valor numérico de las letras. Sus límites, sin embargo, son específicos y rigurosos porque se definen progresivamente a partir de las siete reglas de Hillel para pasar a través

tigación personal: SHAFI, I,: La Risâla, les fondements du droit musulman, Sindbad.Actes Sud, Le Méjan, 1997, pp. 317-338.

49 WINGORT, A.: Responsabilité et sanction en droit talmudique et comparé, Droz, Ginebra, 1998, p. XIX.

Hispania, LX/1, núm. 204 (2000) 103-126 
de las trece middot de Rabbi Ismaél, para llegar a las llamadas treinta y dos middot que deben su nombre a Eliezer ben Yosé ha.Geliliso.

En el derecho canónico se apela expresamente a la analogía en el can. 20 C.J.C., que detalla los cuatro medios para llenar las lagunas. El primero de estos medios es precisamente la analogía en su versión débil de semejanza: «Si certa de re desit expressum praescriptum legis sive generalis sive particularis, norma sumenda est, nisi agitur de ponis applicandis, a legibus latis in similibus, a generalibus juris principiis cum aequitate canonica servatis, a stylo et praxi Curiae Romanae; a communi constantique sententia doctorum». En el derecho canónico, la distinción entre analogia legis (el recurso a leges latas in similibus) y la analogia iuris, con referencia a los principios generales, llevará a Suárez al principio general en virtud del cual es legítima la interpretación extensiva de cualquier ley eclesiástica, incluso penal, porque se funda en el fin de la ley, que carga el acento sobre la salus animarum y la aequitas canonica. Pero tampoco aquí se trata de arbitrariedad, sino de una proporción geométrica que refiere el caso específco al sistema de conjunto y proprociona méritos y culpas entre ellos.

Sin embargo, es importante recordar que, en el campo católico — sustancialmente uniforme en lo que respecta a los procedimientos jurídicos-, la discusión sobre la analogía presenta profundos contrastes, de gran importancia político-teológica. Contra las posiciones dominicanas de Cayetano, que privilegian la analogía de proporcionalidad y que consideran la analogía como diferencia gradual, Suárez sostiene la analogía de los atributos, la analogía de la atribución. Así, en De Legibus, afirma que Dios transmite al pueblo el poder soberano para instituir el poder. Esta soberanía popular no es totalmente distinta de la divina, ni totalmente idéntica a ella: es análoga por participación. De aquí que el poder del Estado sólo será legítimo si el pueblo lo reconoce, lo que resulta bastante más difícil en la interpretación de Cayetano, quien remite a Dios para legitimar el poder político ${ }^{51}$.

10. Tras este viaje, demasiado rápido sin duda, por los conceptos mencionados, volvamos a la reciprocidad. Lo que he tratado de sugerir es que, cuando referimos la reciprocidad equilibrada y la reciprocidad generalizada a las sociedades complejas del Mediterráneo y a las formas económicas, sociales y jurídicas que en ellas predominan, es menester complicar la diferenciación entre esos conceptos, hoy por hoy moneda corriente entre los antropólogos. En efecto, no se trata de identificar transacciones presuntamente altruistas, mode-

30 ABITBOL, G.: Logique du droit talmudique, edición de Sciences Hébraiques, París, 1993, pp. 94-2 10. Para la relación con la equidad, of. rambién COHEN, A.: An Introduction to Jewish Civil Law, Feldheim, Jerusalén-Nueva York, 1991, págs, 145-184.

s1 SUÁREZ, F.: Tractatus de legibus ac Deo legislatore, III, viii, 4-6 y III, xv, 11.12. Se ha utilizado la edición del Corpus Hispanonum de Pase del CSIC, Madrid, 1975, pp. 103-107 y 231-239. Sobre equidad, incluso en relación con la analogía en la interpretación de las leyes, Suárez discute ampliamente, sobre todo en el libro II, xvi, 1-16.

Hispania, LX/1, núm. 204 (2000) 103-126 
ladas sobre el patrón de la asistencia prestada y, si es posible y necesario, recompensada, pero sin la expectativa de una contrapartida material directa de transacciones directas en las que la compensación sea un equivalente consuetudinario e instantáneo del bien recibido ${ }^{52}$. En una sociedad que no tiene una definición clara de la determinación de los valores económicos ${ }^{33}$, que no conoce un mercado impersonal y autorregulado, los problemas de definición del precio justo y del salario justo son complejos y remiten continuamente al concepto de equidad. No se trata de deducir el valor de los bienes intercambiados de una determinación definida en el intercambio, ni de una característica intrínseca de los bienes, sino de construir un sistema de intercambio en el que los valores estén determinados por las características específicas de quienes los intercambian, al punto de que un mismo bien adopte valores distintos según quiénes sean las personas que entran en la transacción: «in salarij taxatione ad boc, ut se cum dispositione iuris conforment multarum rerum rationem habere debebunt, et primo qualitatis personae ${ }^{54}$. ¿Cómo se puede pagar a un médico, que se ocupa de la vida y la muerte?, se pregunta el jurista Zacchia. ¿O a un juez, que se ocupa de lo justo y lo injusto? No puede haber un salario adecuado: se les pagará de manera diferente, no por sus prestaciones, ni por su capacidad, sino de acuerdo con su estatus social, su prestigio, su honor: por eso se denomina «honorarios» al salario del médico y del juez.

Así las cosas, la mezcla de economía y ética, de valores generales de la sociedad y de valores específicos que entran en la teciprocidad que se manifiesta en los intercambios, complica y dificulta la determinación de las medidas -imprescindibles, sin embargo- de la sociedad equitativa y desigual que obedece a estas reglas.

Esto no se opone al esfuerzo de medir y asegurar los valores y dar un orden legible a la sociedad por medio de clasificaciones simplificadoras: esta exigencia será precisamente la que favorezca el progresivo predominio de esquemas uniformes de valor que desplazarán la atención del uso y de las personas al intercambio y a las cosas. Pero nunca habrá una victoria total en ningún campo, y menos aún en el campo jurídico, sector en el que siempre será difícil separar la justicia legal del sentido común de justicia.

Creo que precisamente a través del examen de estos problemas, examen que requetiría sin duda mucho más espacio del que hubiera podido yo disponer

32 Retomo aquí la definición de SAHLINs, M.: Stone Age Economics, Aldine-Atheron, Chicago, 1972, pp. 185-261.

${ }_{33}$ GRENIER, J.Y.: L'Économie dAncien Régime. Un monde de léchange et de lincertitude, Albin Michel, París, 1996, ha planteado el problema con mayor énfasis en la dificulcad para la elaboración de una teoría del valor que el marco cultural distinto en que se colocaba la práctica del incercambio.

54 ZACChilA, L.: De salario seu operariorum mercede, N. Tinassi, Roma, 1658, p. 37. Un ejemplo muy evidente de la relación entre economía y salario justo se encontrará en TRIVELLATO, F.: «Salaires et justice dans les corporations vénitiennes au 17 e siècle: le cas des manufactures de verre», en Annales, Histoire, Sciences Sociales», LIV, 1999, pp. 245-274.

Hippania, LX/1, núm. 204 (2000) 103-126 
aquí, será posible esclarecer algunas diferencias sustanciales en la historia y en las características culturales y antropológicas de diferentes países, e identificar una serie de especificidades mediterráneas que siguen operando todavía hoy.

Si contemplamos en particular Italia, me parece importante observar que la vigencia del derecho canónico junto al positivo, el reconocimiento de la superioridad moral de los clérigos sobre los laicos y prácticas religiosas como la confesión, que proponen por doquier formas lógico-morales a las conciencias individuales, han contribuido a construir una forma específica de sentido común de lo justo, típica de ésta y de otras sociedades católicas en las que no ha tenido lugar una subordinación precoz de la iglesia al Estado. Y esto es también lo que ha contribuido a debilitar las instituciones y a proponer formas intersticiales de acción entre sistemas de normas contradictorias y paralelas.

Por tanto, el tema de la equidad confirma su papel central en la experiencia de los países católicos, como criterio dominante de la justicia distributiva en una sociedad corporativa y jerárquica. $\mathrm{Y}$, aunque con significados diferentes, me ha parecido que también las sociedades de tradición islámica o la tradición jurídica talmúdica presentan caracteres similares. La importancia interpretativa de este concepto excede con mucho, sin embargo, el mero aspecto jurídico para convertirse en criterio de conjunto de la integración y la regulación de todos los aspectos sociales y económicos. La dificultad con que topan los juristas italianos (que he ejemplificado con Vico) en pleno siglo XVII es justamente la de conservar este criterio, aunque reconociéndole naturaleza histórica.

Sin embargo, es imposible imaginar una equidad, una solidaridad y una reciprocidad carentes de rigor: pero se trata de un rigor que requiere una mirada autoritaria que imprima proporción geométrica en los premios y los castigos, con simultánea atención a la especificidad de los casos particulares y de las perspectivas globales de mejora moral del sistema político general.

Las sociedades católicas del mundo mediterráneo han acogido, por cierto, sistemas jurídicos basados en un idioma de igualdad. No obstante, la hipótesis que he querido proponer es que, sobre todo en estas sociedades, la permanencia de un sentido común de equidad en oposición a las normas codificadas goza de tal vigor y de tal virulencia, que ha llegado a ser un aspecto constitutivo de su antropología política. 